\title{
Acceptability of self-collected vaginal samples for HPV testing in an urban and rural population of Madagascar
}

\author{
Céline Broquet ${ }^{\dagger, 1}$, Deborah Triboullier ${ }^{\dagger, 1}$, Sarah Untiet ${ }^{2}$, Sonja Schafer ${ }^{2}$, Patrick Petignat ${ }^{2}$, Pierre Vassilakos ${ }^{3}$
}

\author{
1: Faculty of Medicine, University of Geneva, Geneva, Switzerland \\ 2: Department of Gynecology and Obstetrics, Geneva University Hospitals, Geneva, Switzerland \\ 3: Geneva Foundation for Medical Education and Research, Geneva, Switzerland \\ ${ }^{\dagger}$ Contributed equally
}

\begin{abstract}
Objective: To evaluate the acceptability of self-collected vaginal samples for HPV testing in women living in rural and urban areas of Madagascar.

Materials and methods: Participants were recruited in a health care center (urban group) and smaller affiliated dispensaries (rural group). They were invited to perform unsupervised self-sampling for HPV testing and to answer a questionnaire on socio-demographic information, cervical cancer knowledge and self-sampling acceptability.

Results: A total of 300 women were recruited. Median age was 44.1 years (range 29-65 years) in the urban group and 40.9 years (range 29-65 years) in the rural group. Urban women had improved knowledge on HPV, cervical cancer and cervical cancer screening $(\mathrm{p}<0.05)$ as compared to rural women. Urban women lived closer to a health care center $(\mathrm{P}<0.05)$, had fewer different sexual partners $(\mathrm{P}<0.05)$ and later first sexual intercourse $(\mathrm{p}=0.07)$. Unlike urban women, most rural women were married $(\mathrm{p}<0.05)$.

Conclusion: Acceptability of self-sampling for HPV testing was similarly excellent in both groups despite their difference in terms of socio-demographic factors and knowledge about cervical cancer.

Keywords: Madagascar, HPV DNA Tests, Cervical Intraepithelial Neoplasia

DOI: http://dx.doi.org/10.4314/ahs.v15i3.8

Cite as: Broquet C, Triboullier D, Untiet S, Schafer S, Petignat P, Vassilakos P. Acceptability of self-collected vaginal samples for HPV testing in an urban and rural population of Madagascar. Afri Health Sci. 2015;15(3):755-61. doi: http://dx.doiorg/10.4314/abs.v15i3.8
\end{abstract}

\section{Introduction}

Little data is available on cervical cancer in Madagascar although according to estimations by the World Health Organization (WHO), about 1553 women are diagnosed and 1085 die every year from this disease. ${ }^{1}$ Among women aged between 15 and 44 years, cervical cancer overtakes breast cancer as the most frequent form of cancer. Five million women aged 15 years and older are at risk, and in 2025 more than 2000 women are expected to die from this illness. ${ }^{1}$ In 2003, the Institut Pasteur de Madagascar conducted a retrospective study on tissue samples. Their data showed that cervical cancer is the leading cause of death caused by cancer in women aged between 36 to 45 years. $^{2}$

\section{Corresponding author: \\ Céline Broquet \\ Rue Michel-Chauvet, 7 \\ 1208 GENEVA, Switzerland \\ +41789118139 \\ E-mail: céline.broquet@etu.unige.ch}

The high cervical cancer prevalence in developing countries is mostly due to the absence of screening, which would allow pre-cancer detection and treatment. Pap smear, the currently most common screening test in developed countries, is too expensive and requires qualified pathologists to evaluate the results. Visual Inspection methods with Acetic Acid (VIA) or Lugol's Iodine (VILI) are low-cost and easy to perform but results are extremely dependent on the examiner's experience.

In a recent meta-analysis the sensitivity of VIA in detecting CIN II and III lesions varies from 14 to $95 \%$ and specificity from 14 to $98 \% .^{3} \mathrm{~A}$ high-quality VIA has an average sensitivity of $50 \%$ and a specificity reaching $85 \% .^{3}$ Another option, recommended by the World Health Organization, is testing for high-risk human papilloma virus (HPV) infection. ${ }^{4}$ The test shows high sensitivity and offers the possibility of self-vaginal sampling. Self-collected vaginal swabs are sent to the lab and analyzed with molecular technology. As HPV testing has high sensitivity it is unlikely that women who get 
a negative test result develop cancerous cervical lesions within the following 5 to10 years.

The introduction of a screening test is a complex process and before implementing a method, women's willingness as well as the acceptability of the test should be explored in the context. Differences between urban and rural populations may be important because of different risk factors such as marital status, number of sexual lifetime partners or age at first sexual intercourse. This explains why our study's aim was to explore the acceptability of self-vaginal sampling as an alternative screening method in two different communities of Madagascar. We wanted to define the impact of sociodemographic factors on the women's willingness to perform self-vaginal sampling, as well as to investigate the influence of cervical cancer knowledge on self-sampling acceptability.

\section{Methods}

Setting; This research project is embedded in a longterm study on cervical cancer prevention in Madagascar aiming to develop an adapted cervical cancer screening and treatment approach for the country. The Ministry of Health, Madagascar (07.06.2013) granted Ethic's approval for this study. All participants were informed and had to complete informed consent forms before inclusion. The study was conducted between July 18th and August $18^{\text {th }}$ in Saint-Damien health care center, which is situated near to Nosy Be Island, $500 \mathrm{~km}$ Northeast of Antananarivo. ${ }^{5}$

\section{Participants}

Inclusion criteria; We recruited 150 women in Saint-Damien health care center (urban group), and 150 women in smaller affiliated dispensaries in the surrounding area (rural group). We included women aged between 30 and 65 years. Exclusion criteria were former conisation or hysterectomy and pregnancy beyond 20 weeks.

Procedure; Participants in both groups received educational intervention on cancer and HPV as it was previously described. ${ }^{6}$ It was followed by information and a flyer with drawings on how to perform self-vaginal sampling (referred to as Self-HPV), written in local dialect language. At the same time they received a sterile, flocked swab and transportation tube (ESwab, Copan, Brescia, Italy). Self-sampling was always performed without supervision: women were tested in Saint-Damien or in a smaller dispensary depending on their affiliated group. Then, they were invited to answer a small questionnaire, which consisted of four parts: (1) socio-demographic information, (2) awareness and knowledge about cervical cancer, cervical cancer screening and HPV, (3) self-sampling acceptability, (4) women's interest in receiving further information. More information was provided after answering the questionnaire. The samples were stored in the refrigerator for the duration of the study. Thereafter, they were transported at Unilabs Lausanne, Switzerland by air. A portable refrigerator was used to maintain adequate temperature. The analyses began just a few days after the arrival in Switzerland.

Both groups were tested for HPV by a real-time PCR (AnyplexTM II HPV28 test, Seegene, Seoul, Korea) and women who got a positive result were followed up in Saint-Damien Health care center where they received follow-up recommendations and medical management if necessary.

Evaluation of knowledge; We evaluated basic knowledge on cervical cancer with following questions: (1) Does HPV infection lead to AIDS? $(\mathrm{Y} / \mathrm{N} /$ does not know) (2) Can HPV infection cause cervical cancer? (Y/N/does not know) (3) Is HPV infection a STI? (Y/N/does not know) (4) Can men be infected with HPV and spread the disease? (Y/N/does not know) (5) Is there a way to prevent the infection? $(\mathrm{Y} / \mathrm{N} / \mathrm{does}$ not know) (6) Is symptomatic cervical cancer curable? (Y/N/does not know). Basic knowledge on cervical cancer was classified in poor (0-2 right answers out of 6 questions), mediocre (3-4 out of 6 ) or good (5-6 out of 6$)$.

Data analysis; Socio-demographic data was analyzed for comparability by chi-square test. Self-HPV acceptability and effectiveness in both groups was analyzed with chi-square test and Extended Mantel-Haenszel chi square test. HR-HPV and LR-HPV prevalence in both groups was compared using Fisher-exact test. The tests were considered as statistically significant when the p-value was $<0.05$. All statistical analysis was performed using OpenEpi website. ${ }^{7}$

\section{Results}

Participant's characteristics and settings $(\mathrm{N}=300)$. All approached women agreed to participate. A total of 300 women between 30 and 65 years were included: 150 in Saint-Damien health care center (urban group), 150 in the surrounding villages (rural group). The mean age in the urban group was 44.1 years (range 29-65 years; $\mathrm{p}<0.05$ ).(Table 1) Many of the participants living in the urban area were married $(47.3 \% ; \mathrm{p}<0.05)$ and had fin- 
ished high school $(56.7 \% ; \mathrm{p}<0.05)$. The average number of sexual lifetime partners was 4.9 and the mean age at first sexual intercourse was 17.3 years. For those living in the rural area, mean age was 40.9 years (range 29-65 years; $\mathrm{p}<0.05)$. Most were married $(72.0 \%$; $<<0.05)$ but few of them had finished high school $(30.0 \% ; \mathrm{p}<0.05)$. The mean age at first sexual intercourse was earlier $(16.5$ years: $\mathrm{p}<0.05)$ and the average number of sexual lifetime partners was higher $(6.1, \mathrm{p}=0.07)$ compared to the urban group.

Table 1: Socio-demographic characteristics of participants $(\mathrm{N}=300)$

\begin{tabular}{|c|c|c|c|}
\hline Characteristics & $\mathrm{N}(\%)$ & $\mathrm{N}(\%)$ & P-Value* \\
\hline $\begin{array}{l}\text { Age } \\
\text { Mean (range) } \\
25-29 \\
30-39 \\
40-49 \\
50-59 \\
60-65\end{array}$ & $\begin{array}{l}44.1(29-65) \\
4(2.7) \\
53(35.3) \\
40(26.7) \\
44(29.3) \\
9(6.0)\end{array}$ & $\begin{array}{l}40,9(29-65) \\
2(1.3) \\
65(43.3) \\
59(39.3) \\
19(12.7) \\
5(3.3)\end{array}$ & $P<0.05^{*}$ \\
\hline $\begin{array}{l}\text { Marital status } \\
\text { Single/widowed } \\
\text { Divorced/separated }\end{array}$ & $\begin{array}{l}73(48.7) \\
6(4.0)\end{array}$ & $\begin{array}{l}42(28.0) \\
0(0.0)\end{array}$ & $P<0.05^{*}$ \\
\hline $\begin{array}{l}\text { Education } \\
\text { No formal education } \\
\text { Primary } \\
\text { High School } \\
\text { University }\end{array}$ & $\begin{array}{l}7(4.7) \\
52(34.7) \\
85(56.7) \\
6(4.0)\end{array}$ & $\begin{array}{l}31(20.7) \\
74(49.3) \\
45(30.0) \\
0(0.0)\end{array}$ & $P<0.05^{*}$ \\
\hline $\begin{array}{l}\text { Time to closest dis } \\
<30 \mathrm{~min} \\
30-50 \mathrm{~min} \\
60-119 \mathrm{~min} \\
>120 \mathrm{~min}\end{array}$ & $\begin{array}{l}100(66.7) \\
32(21.3) \\
6(4.0) \\
12(8.0)\end{array}$ & $\begin{array}{l}51(34.0) \\
34(22.7) \\
29(19.3) \\
36(24.0)\end{array}$ & $P<0.05^{*}$ \\
\hline $\begin{array}{l}\text { Number of differen } \\
\text { Meán (range) }\end{array}$ & $4.9(1-30)$ & $6.1(1-30)$ & $P=0.07^{* *}$ \\
\hline $\begin{array}{l}\text { Age at first sexual } \\
\text { Mean (range) }\end{array}$ & $17.3(13-30)$ & $16.5(13-26)$ & $P<0.05^{* *}$ \\
\hline
\end{tabular}

Note: *analyzed with chi-square test, ${ }^{* *}$ analyzed with unpaired t-test

Awareness and knowledge about cervical cancer ( $\mathbf{N}=46)$.

Out of our sample $46(30.7 \%)$ women had ever heard about cervical cancer: $39(26.0 \%)$ lived in town and 7 $(4.7 \%)$ in rural areas. The main sources of knowledge were midwives and physicians (66.6\%) in the urban group, and radio emissions (100.0\%) in rural areas. Unlike women living in rural areas whose basic knowledge was mostly mediocre $(57.1 \%$; $\mathrm{p}<0.05)$, most women living in town showed good basic knowledge on cervical cancer $(59.0 \% ; \mathrm{p}<0.05)$. (Table 2 ) 
Table 2: Awareness and knowledge about cervical cancer $(\mathrm{N}=46)$

\begin{tabular}{llll}
\hline Characteristics & $\mathrm{N}(\%)$ & $\mathrm{N}(\%)$ & P-Value $^{*}$ \\
& Urban (N=150) & Rural (N=150) & \\
\hline & & & \\
cancer (N=46) & & & \\
Yes & $39(26.0)$ & $7(4.7)$ & $\mathrm{P}<0.05^{*}$ \\
No & $111(74.0)$ & $143(95.3)$ & \\
& & & \\
Where heard about cervical & & & \\
$\begin{array}{l}\text { Radio } \\
\text { Medical center }\end{array}$ & $9(23.1)$ & $7(100.0)$ & \\
Other (school. village meeting) & $26(66.6)$ & $0(0.0)$ & \\
& $4(10.26)$ & $0(0.0)$ & \\
Basic knowledge about & & & \\
cervical cancer* & & & \\
Good & & $1(14.3)$ & \\
Mediocre & $23(59.0)$ & $4(57.1)$ & \\
Poor & $13(33.3)$ & $2(28.6)$ & \\
\hline
\end{tabular}

Note: Basic knowledge: poor: 0 to 2 correct answer out of 6 questions; mediocre: 3 to 4 correct answers out of 6 questions; good: 5 to 6 correct answers ${ }^{*}$ Analyzed with Fisher exact test, **analyzed with Extended Mantel-Haenszel chi square

Acceptability and feasibility of self-sampling for HPV testing $(\mathbf{N}=300)$

All women $(100 \%)$ felt strongly concerned by cervical cancer screening $(\mathrm{p}=0.25)$. Most women in the urban group felt no pain $(73.3 \%$ : $\mathrm{p}=0.48)$, no discomfort $(62.7 \% ; \mathrm{p}=0.12)$ and no embarrassment $(85.3 \%$; $\mathrm{p}=0.46)$. They had the feeling that the procedure was easy to execute $(87.3 \%)$ and felt confident they had performed the test correctly $(96.7 \%)$. Similar observations were made in rural areas. Both groups (100\%) would agree to undergo regular cervical cancer screening. In the urban $(88.0 \%)$ as in the rural group $(71.3 \%)$, health care centers were usually mentioned as the best place to get screened. Only 2 women $(1.33 \%)$ from Saint-Damien, and another $2(1.33 \%)$ from rural areas said the procedure was too complicated and that they wouldn't recommend it. All participants (100.0\%) would agree to come back if they tested HPV positive. Most women $(98.0 \%$ from town and $80.7 \%$ in the rural group) showed high interest in receiving further information about cervical cancer, screening and HPV. (Table 3) 


$\begin{array}{lll}\text { N (\%) } & \text { N (\%) } & \text { P-Value* } \\ \text { Urban } & \text { Rural } & \end{array}$

\section{Concerned by screening}

Not at all

Slightly

Moderately

Strongly

$\begin{array}{ccc}0(0.0) & 0(0.0) & \\ 0(0.0) & 0(0.0) & \\ 0(0.0) & 3(2.00) & \mathrm{P}=0.25 \\ 150(100.0) & 147(98.0) & \end{array}$

\section{Embarrassment}

$\begin{array}{lccc}\text { Low } & 17(11.3) & 24(16.0) & \mathrm{P}=0.46 \\ \text { Moderate } & 5(3.3) & 4(2.7) & \\ \text { High } & 0(0.0) & 0(0.0) & \\ & & & \\ \text { Pain } & & & \\ \text { Low } & 28(18.7) & 21(14.0) & \mathrm{P}=0.48 \\ \text { Moderate } & 10(6.7) & 9(6.0) & \\ \text { High } & 2(1.3) & 2(1.3) & \end{array}$

\begin{tabular}{lccc} 
Discomfort & & & \\
None & $94(62.7)$ & $122(81.3)$ & \\
Low & $43(28.7)$ & $16(10.7)$ & $\mathrm{p}=0.12$ \\
Moderate & $10(6.7)$ & $9(6.0)$ & \\
High & $3(2.0)$ & $3(2.0)$ & \\
\hline
\end{tabular}

Best place to perform testing

Medical center

$132(88.0)$

107 (71.3)

$p<0.05^{\star *}$

Home

Don't know

$4(2.7)$

$1(0.7)$

34 (22.7)

$13(8.7)$

$0(0.0)$

Don't care

(home/medical center)

9 (6.0)

Recommend method

(why)

Yes (easy to perform)

No (too difficult)

147 (98.0)

2 (1.33)

$148(98.67)$

1 (0.66)

$2(1.33)$

$p=0.46^{* *}$

Don't know

Interested in further

information

\begin{tabular}{lccc} 
Not at all & $2(1.3)$ & $8(5.3)$ & \\
Slightly & $0(0.0)$ & $3(2.0)$ & $\mathrm{p}<0.05^{* *}$ \\
Moderate & $1(0.7)$ & $18(12.0)$ & \\
Very much & $147(98.0)$ & $121(80.7)$ & \\
\hline
\end{tabular}

Note: *Analyzed with Extended Mantel-Haenszel chi square test; ** analyzed with Mann-Whitney U-Test 


\section{Discussion}

In Eastern Madagascar, lack of medical resources, financial means and health knowledge explains the absence of cervical cancer screening. Our study was a part of a collaborative project organized by the Geneva University Hospitals, the Geneva Faculty of Medicine, and Saint Damien Health Care Center, Ambanja, to promote innovative methods for cervical cancer screening strategy adapted for low-resource settings such as Madagascar.

As practical difficulties encountered in the field often impair screening strategies, a surprisingly good result in this context is that out of 298 tested samples only one had to be excluded due to an invalid result. It should be noted that each women used only one swab, and that only one sample per patient was taken.

Our study supports that acceptability and willingness of women to perform self-sampling for HPV testing is high, even though the socio-demographic composition of our study sample is quite heterogeneous. Indeed, rural women usually live further from a health care center, are less educated and have a shorter life expectancy. They have their first sexual intercourse earlier, have more sexual lifetime partners, more children and are younger when they give birth for the first time. Malagasy women were very interested in seeking medical care and showed high level of concern about health issues. They all wanted to receive further information about cervical cancer, cervical cancer screening and HPV. Women living in urban areas as well as those from rural areas both felt very involved in cervical cancer screening.

There was significant higher awareness of cervical cancer and cervical cancer screening among women living in town compared to those living in rural areas, probably because they usually lived closer to a health care center. STIs such as syphilis are very common in Madagascar, unlike HIV infection and AIDS which reach an infection rate of less than $1 \% 0^{8,9}$. It is therefore likely that by entering into a care process while seeking medical care women receive general information about STIs. (unpublished data). We noted that HPV and cervical cancer knowledge had no influence on the acceptance rate of the test, which is probably explained by the fact that women agree to get cervical cancer screening because they believe in their health system. We believe that carefully oriented education and information of the participants plays a significant role in the acceptance of the screening test. This was also demonstrated in a previous study conducted in Cameroon. ${ }^{6}$
A shortcoming of our study is that participants were recruited on a voluntary basis. It is possible that this self-selection may bias the outcomes as well as the desirability of the screening method. Indeed, it is likely that the burden of disease is the heaviest among the women that are the hardest to reach. It is also possible that women might have commented more positive on self-sampling for HPV testing feeling obliged, as the health care center of Saint-Damien is very renowned in the area and supported the study. The strength of our study is that we explored two different populations who had never had the opportunity to get tested for HPV infection and cervical cancer. We believe that the results obtained in these two groups have the potential to be extrapolated to the population of this area. Another strength of our study is the very low rate of invalid samples.

Finally, it must be underlined that in our study HPV testing was performed in Switzerland. This approach is impractical in a routine context. Therefore besides self$\mathrm{HPV}$, it is necessary to introduce a point-of-care and rapid HPV assay, which could facilitate same-day screen and management strategies. Thus repeated visits may be minimized, allowing most of the eligible women to participate in the program

\section{Conclusion}

We observed a high acceptability rate of the method in both groups although risk and demographic factors as well knowledge about cervical cancer were different in the two communities. Our study supports the possibility to progressively implement a cervical screening program in this low-resource setting using a self-sampling for HPV testing method.

\section{Conflict of interest}

The authors declare to have none.

\section{References}

1. WHO | Human papillomavirus (HPV) and cervical cancer [Internet]. WHO. [cited 2014 May 3]. Available from: http://www.who.int/mediacentre/factsheets/ fs $380 /$ en/

2. Raharisolo Vololonantenaina CR, Rabarijaona LP, Soares JL, Rasendramino M, Pecarrere JL, Khun $\mathrm{H}$, et al. Bilan des cancers du col utérin diagnostiqués à l'Institut Pasteur de Madagascar de 1992 a 2002. Arch Inst Pasteur Madagascar 2003;69(1-2):77-81.

3. Sankaranarayanan R, Nessa A, Pulikattil Okkuru E, 
Dangou JM. Visual inspection methods for cervical cancer prevention. Best Pract Res Clin Obstet and Gynaecol 2012;26(2):221-232.

4. WHO | Human papillomavirus (HPV) and cervical cancer [Internet]. WHO. [cited 2015 February 16]. Available from: http://apps.who.int/iris/bitstream/10665/94830/1/978924 1548694_eng.pdf

5. Action Madagascar [Internet]. Fribourg: Action Madagascar; 2002 [cited 2013 Jun 23]; Available from: http://www.actionmadagascar.ch/cmc/

6. Crofts V, Flahault E, Tebeu PM, Untiet S, Kengne Fosso G, Boulvain M, Vassilakos P, Petignat P. Education efforts may contribute to wider acceptance of human papillomavirus self-sampling. International Journal of Women's Health 2015:7 149- PubMed ;154
7. Sullivan KM, Dean A, Soe MM. OpenEpi: A Webbased Epidemiologic and Statistical Calculator for Public Health. Public Health Rep 2009;124(3):471 PubMed-4. 8. Xueref S, Holianjavony J, Daniel R, Kerouedan D, Fabry J, Vanhems P. The absence of HIV seropositivity contrasts with a high prevalence of markers of sexually transmitted infections among registered female sex workers in Toliary, Madagascar. Trop Med Int Health 2003;8(1):60 PubMed -6.

9. USAID [Internet]. USAID Madagascar - HIV/AIDS Health Profile. 2012 [cited 2014 Nov 6]; Available from: http://transition.usaid.gov/our_work/global_health/ aids/Countries/africa/madagascar_profile.pdf 